\title{
III. Description of a new compensation pendulum
}

\section{Mr. H. Ward}

To cite this article: Mr. H. Ward (1808) III. Description of a new compensation pendulum, Philosophical Magazine Series 1, 32:125, 22-29, DOI: 10.1080/14786440808562753

To link to this article: http://dx.doi.org/10.1080/14786440808562753

$$
\text { 册 Published online: } 18 \text { May } 2009 .
$$

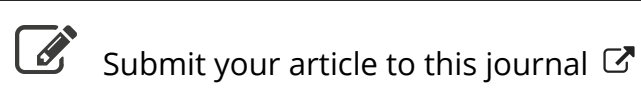

\footnotetext{
Џlll Article views: 2
}

Q View related articles $₫$ 
their merits as critics, by contrasting their lucubrations with the sublime discoverics of sir Isaac Newton? Or has the science of optics a more intimate alliance with chemistry than with criticism? When an individual arrogantly invites comparisons, he deserves to be bumbled; but to drag an unassuming, unoffending labourer in any science, into contrast with a luminary in another science, for the purpose of degradation, is, to say the least of it, an act of wanton cruelty, and savours more of envy than of sound criticism. EDrT.

III. Description of a new Compensation Pendulum. By Mr. H. WARD, of Blandford, Dorsetshire*.

Reference to the Engraving. Plate II.

Fig. 2, 3, 4, 5 .

Fig. 2. is a side view of the pendulum rod when together. hhii are two flat rods or bars of iron, about an eighth of an incb thick. $k k$ is a bar of zinc interposed between them, and is nearly a quarter of an inch thick. The corners of the iron bars are bevelled off, that they may ineet with less resistance from the air; and it likewise gives them a much lighter appearance. These bars are kept together by means of three screws 111 , which pass through oblong holes in $h h$ and $k k$, and screw inio $i i$. The bar $h h$ is connecied to the one $k h$ by the screw $m$, which I call the adjusting screw. This screw is tapped into $h \mathrm{~h}$, and passes barely through $k k$; but that part of the screw which enters $k k$ has its threads turned off. The bar $i i$ has a shoulder at its upper end turned at right angles, and bears at the top of the zinc bar $k k$, and is supported by it. It is necessary to have several holes for the screw $m$ in order to adjust the compensation. See Fig. 1, 6.-Fig. 3, 4, 5. are a side view of each bar separately. Fig. 6. shows the flat side of the zinc bar. Fig. 1. is a front view of the pendulum-rod when screwed together. The letters bave the same reference to the different figures.

* From Transuctions of the Saciety for the Encoutagement of Arts, Manufactures, and Cummerse, for 1807 ; but with corrections communicated by the author - The silver medal of the Society was voted to Mr. Ward for this invention. 
Now it is evident, that if any degree of heat or cold be applied to this compound rod, the one of zinc expands and contracts as much as the two iron ones together; the distance from the point of suspension to the centre of oscillation must remain the same.

In proportioning the length of the bars, I made use of Mr. Smeaton's table of expansion of metals in the 48 th vol. of Philosophical Transactions ; where he shows, by experiments made with a pyrometer, that the expansion of iron is to that of unhammered zinc, with the same degree of heat, as 151 to 353 , and to that of zinc hammered, half an inch per foot, as 151 to 373 . This great expanding property of zinc renders it in theory extremely fit for the purpose of compensation in a pendulum, and I was desirous of knowing if it would answer in practice, and likewise the exact proportion that was requisite to answer the intended purpose.

I made two regulators whose pendulums were composed of iron and zinc, as above described, with this difference, however, that one had a detached escapement of a particular construction; the zinc bar was not hammered, the ball of a lenticular form, and weighed twenty pounds, its arc of vibration nearly five degrees. The other had a simple remontoir escapement, the zinc bar was hammered half an inch per foot, the ball, of spherical form, weighed forty-six pounds, and vibrated two degrees and three quarters.

These regulators were both placed in the same room, and their cases firmly fixed to the wall; the pendulums were suspended from a stout brass cock, screwed to the back of their respective cases. In the inside of each case, and immediately behind the pendulum rod, was hung a thermometer, for the purpose of comparing the degrees of heat. I adjusted them to mean time nearly by corresponding altitudes of the sun. After baving compared them together for several days, I found that the one which had the hammered zinc bar went somewhat faster when the air of the room was heated by a fire in the grate than the other did. Hence I concluded that the difference of expansion of hammered and unhammered zinc was greater than Mr. Smeaton made it, at least it appeared so in this instance. 
But to dutermine whether the length of the hammered zinc bar was accurately proportioned to that of the iron ones I wished next to prove, without wating that length of time that Nature would require to produce a sufficient alteration in the temperature of the air, I proceeded to make the following experiment: I caused to be made a tin tube six feet long, and two inches and a half diameter at its larger end, from whence it gradually tapered to the other, which was only half an inch diameter. Within the case, and as far from the pendulum as possible, I placed this tube; the smaller end was carried through a hole in the top of the case, and projected a few inches above it. In the lower end of the tube was inserted the nozzle of a lamp, and immediately under it, in the bottom of the case, was a hole of an inch diameter to supply the lamp with air. By this means the tube would communicate as much heat to the internal air, as to raise the thermometer about thirty-five degrees.

Previous to the lamp being put in the case, I nade both pendulums vibrate exactly together; and after an interval of twenty-four hours, the one with the hammered zinc bar had gained, as near as I could judge, one tenth of a second. The mean height of the thermometer was fifty-tbree degrees. I now lighted the lamp, and in about four hours every part appeared to be thoroughly heated, and the thermometer arrived at its maximum, which was eiglity-cight degrees; at this point it continued with little variation. While the beat was increasing I found the motion of the pendulum was accelerated. I again made them beat exactly together, and in about ten hours after, the heated pendulum had gained one second; the thermometer in the other case continuing nearly the same. The lamp was then taken out, and as soon as the parts were cooled, and both thermometers showed the same degree, $l$ adjusted the beat of the pendulums as before, and at the end of twenty-four hours I found the pendulum that had been heated kejt precisely the sume rate as it did before the experiment was made.

By this experiment it appeared evident that the zinc bar was considerably too long. The pendulum was then taken down, to have more holes made for the adjusting screw; 
and after many repeated trials with the lamp and tube, as before, I found the length of the zinc bar to be 22 inches, and consequevtly the length of the iron ones together 39.2 plus 22 equal to 61.2 inches, or, the expansion and contraction of iron to that of zinc hammercd, half an inch per foot, as 151 to 420 .

Having thus far satisfied myself with the hammered zinc bar, I proceeded to make similar trials with the one that was unhammered: in doing which a circumstance occurred that I cannot account for, that when the air in the case was rarefied by means of the lamp and tube, the arc of vibration would be about half a kegree less than it was before the lamp was applied, which is directly contrary to what I should expect would have taken place. I aftcrwards found that the other pendulum , was affected the same way, but in an extreme small degree, which, without doubt, was in consequence of the ball being much heavier, and vibrating a smaller arc. In taking the rate of the clock when the lamp was in the case, I at first computed from theory the error that would arise by such a diminution of the arc, and allowed for it accordingly; but doubting whether the unlocking of the swing wheel might not, from a decrease of velocity in the pendulum, have a greater tendency to retard its vibrations, I therefore thought the experiment would be rendered more accurate if the maintaining power was increased until the arc of vibration should be the same. Afier several trials I found the length of the unhammered zinc bar to be about twenty-nine inches, which agrees pretty nearly with Mr. Smeaton's experiment; that is, in regard to the relative expansion of iron and unbammered zinc.

The zinc bar of the pendulum, which I here send to the Society of $\Lambda$ rts, was hammered three quarters of an inch per foot; and by making experiments with it as I had done with the other two, 1 found the length of it to he twentytwo inches, which is exactly the same length as the one that was hammered half an inch per foot, so that it seems nothing is gained after hammering it to a certain degree; but I cannot think that any rule can be laid down to enable us to judge of the degree of expansion that will take place with a determinate 
determinate increase of heat, from the quantity that is extended by the hammer; much depends on the degree of curvature and polish of the stake and hammer, and probably on the heating of the bar at the time; for it is necessary to heat it a little hotter than boiling water, otherwise it will crack in hammering.

In all these experiments it is to be understood that the ball of the pendulum was suspended by its centre; but if the ball be made to rest on its lower edge, the expansion and contraction of it must bo taken into consideration.

It has been the opinion of some mechanists that zine is an unfit substance for a compensation pendulum, because they have thought it too soft for the purpose, and that atter being heated or cooled to a considerable degree, it does not return to its original dimensions. If that was really the case, no doubt but it would be a general one, common to all metals in a greater or less degree; but from the experiments and obstrvations I have made on zinc pendulums, I am fully satisfied there is no foundation whatever for such an opinion. Some time in the latter part of last summer, I however noticed a circumstance that made me doubt the matter - for when I first used any zinc pendulum, I could never bring the clock to keep the same rate two days together, but it was continually retarded, whether I used the lamp or not; and had 1 not before observed a similar effect on a lever pendulum that was made of brass and steel, I should bave ascribed the cause wholly to the softness of the zinc bar; but by constantly comparing its daily rate with one that had been going a longer time, I found this retarding property gradually wore off, and in less than a month would bccome quite settled to the rate that it would afterwards keep. By subsequent experiments with the lamp too, I have constantly found that all the pendulums I have hitherto tried kept precisely the same rate, both during the time they were heated (provided they were properly adjusted) and afterwards, as they had done before. The cause of this retardation appears to me to be, that the points of contact of the different pieces, which compose the pendulum, are more closely connected after a little time than they are at 
first, that is, those points of contact do, by the weight of the ball, yield to each other in a small degree, until they get a broader bearing.

The advantages of this pendulum are, 1 st, That from its simplicity it will never fail to have the desired effect. 2dly, That no extraordinary care is requisite in executing it. 3dly, That the compensation may be increased or diminished with the greatest ease, without stopping the clock more than a minute, by making fast one of the screws that keep the rods together whilst the adjusting screw is removing, taking care to release it again afterwards. And 4 thly, That it can be manufactured for less expense than any other compensation pendulum hitherto published.

N.B. The compensation of this pendulum which I now send to the Society of Arts is properly adjusted, at least very near the truth. The holes for the adjusting screw are made at such a distance from each other, that by removing the screw one hole, it will produce an alteration in the going of the clock about a quarter of a second per day with a change of thirty degrees of Fahrenheit's thermometer.

$$
\text { SIR, }
$$

Permit me to state to you the observations I have made since my compensation-pendulum was laid before the Society.

The regulator, with the hammered zinc bar, and ball of forty-six pounds weight, was firmly fixed to a brick wall at the top of my house. The adjustment of the length of the bars, by means of a lamp, was repeated as before. There was, however, an alteration necessary to be noticed; the ball of the pendulum rested on its lower extremity, instead of being suspended by its centre. I prefer this method, as being less liable to error if the rods should be sooner affected by heat or cold than the ball. The length of the zinc bar, as ascertained by the lamp, was now found to be 20 inches and a quarter.

The clock was then set to mean time, and suffered to go without alteration; the result is exhibited in the following table. 
Exror of clock

1806. at tine of observation.

$s$.

$\begin{array}{lrlr}\text { March } 21 & & 0 \cdot 0 \\ \text { April } & 8 & \text { Fast } & 2 \cdot 8 \\ \text { May } & 10 & \text { Slow } & 8.7 \\ & 26 & - & 21 \cdot 5 \\ \text { June } & 21 & - & 500\end{array}$

Number of days between the observation.

Daily rate.

s.

Gain 0.15

Loss 0.33

$16-0.80$

$26-1 \cdot 10$

Increased the compensation for heat and cold 6 holes equal to 4 inches and 3 quarters; or, the length of the zinc bar 25 inches. The clock was again set to mean time.

\begin{tabular}{|c|c|c|c|c|c|c|}
\hline & & & $s$. & & & $s$. \\
\hline July & 1 & & 0.0 & g6 & Loss & 0.36 \\
\hline & 27 & Slow & $9 \cdot 3$ & 13 & - & 0.21 \\
\hline Aug. & 9 & - & 12.0 & 7 & - & 0.31 \\
\hline ept. & 16 & $\rightarrow$ & $\begin{array}{l}14^{\circ} 2 \\
04^{\circ} 0\end{array}$ & 28 & - & $0 \cdot 34$ \\
\hline$s$ & $\begin{array}{l}13 \\
25\end{array}$ & - & 35.5 & 12 & - & 0.80 \\
\hline & 17 & - & $52 \cdot 1$ & 22 & 一 & 0.84 \\
\hline
\end{tabular}

Althongh a thermometer was attached to the clock, I could not, from a necessary attendance to business, register it regularly. The difference of its height in March and June may be taken at about 22 degrees, and in July and Octobur 14 degrees, without much error.

On comparing it with the rate of the clock, the compensation, in the latter case, appears nearly as much too great, as it was in the first too small. The true length of the zinc bar nught to be about 23 inches.

The length of the zinc bar, thus ascertained, is one inch and three quarters more than the experiment by the lamp makes it: indeed, I have always suspected there might be sone error in that experiment, on account of the length of the arc of vibration being affected by it.

Having no means of finding the time accurately but by equal altudes, I could not get so many obervations as might be wished. I trust, however, these will not be found altugether useless. I am, sir, your obcdient servant,

Plandford,

HENhY WARD.

October 21, 1806.

To C. TAYLOR, M.D. Sec. 
Description of a new Compensation Pendulum. $\quad 29$

A Register of the going of the clock with the unhammered zinc bar twenty-nine inches in length, determined from observations of the sun's transit over the meridian.

$$
\begin{aligned}
& \begin{array}{l}
\text { Error of clock } \\
\text { at time of ob- Daily rate. }
\end{array} \\
& \text { 1807. } m \text {. } s \text {. } \\
& \begin{array}{rrrrrrr}
\text { April } & 12 & \text { Slow } & 0 & 1 & \text { Gain } & 0 \cdot 4 \\
& 20 & \text { Fast } & 0 & 2 & & \\
\text { May } & 1 & - & 0 & 10 & & - \\
\text { June } & 8 & - & 1 & 1 & & 1 \cdot 3
\end{array}
\end{aligned}
$$

20. Clock stopped, having been forgot to be wound up. It was set going again.

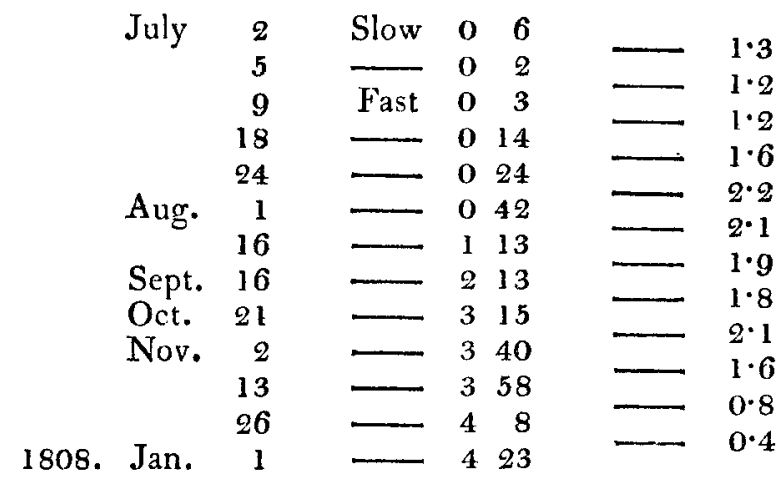

24. Clock stopped, swing to a fault in the escapement. It was afterwards altered. February 16, set going again.

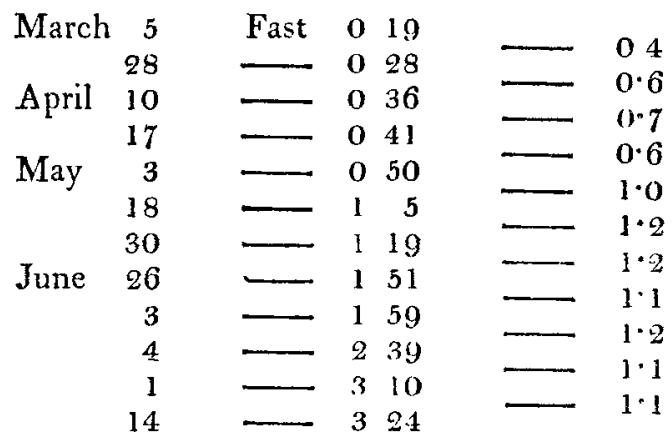

N.B. This register has been made since the foregoing account was sent to the Society. 


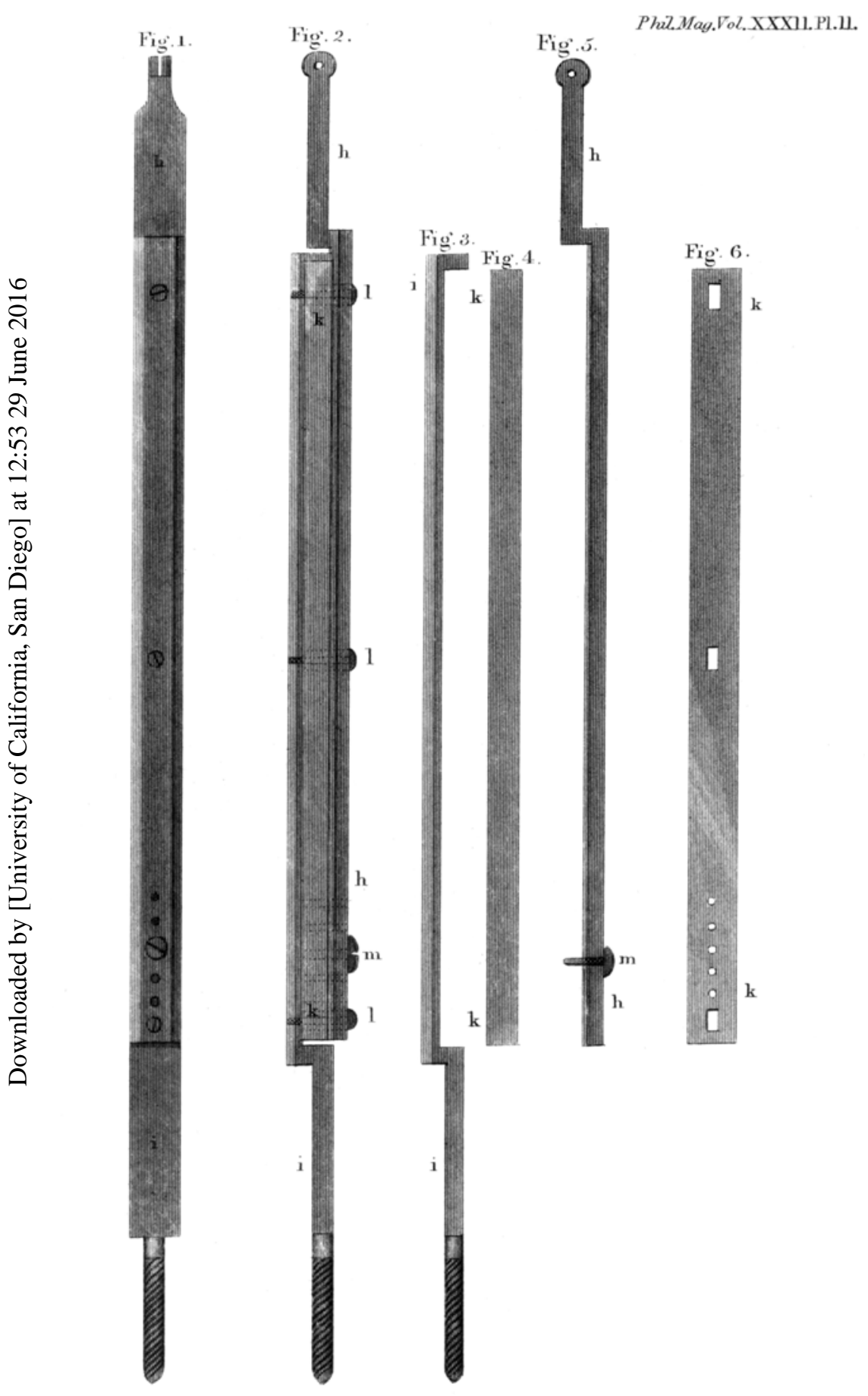

H. Want, inr." 